\title{
Multiobjective Design of Turbo Injection Mode for Axial Flux Motor in Plastic Injection Molding Machine by Particle Swarm Optimization
}

\author{
Jian-Long Kuo and Meng-Ti Chang \\ Department of Mechanical A.E., National Kaohsiung First University of Science and Technology, Nanzih, Kaohsiung 811, Taiwan \\ Correspondence should be addressed to Jian-Long Kuo; jlkuo@nkfust.edu.tw
}

Received 29 September 2014; Accepted 26 December 2014

Academic Editor: Mo Li

Copyright (C) 2015 J.-L. Kuo and M.-T. Chang. This is an open access article distributed under the Creative Commons Attribution License, which permits unrestricted use, distribution, and reproduction in any medium, provided the original work is properly cited.

\begin{abstract}
This paper proposes a turbo injection mode (TIM) for an axial flux motor to apply onto injection molding machine. Since the injection molding machine requires different speed and force parameters setting when finishing a complete injection process. The interleaved winding structure in the motor provides two different injection levels to provide enough injection forces. Two wyewye windings are designed to switch two control modes conveniently. Wye-wye configuration is used to switch two force levels for the motor. When only one set of wye-winding is energized, field weakening function is achieved. Both of the torque and speed increase under field weakening operation. To achieve two control objectives for torque and speed of the motor, fuzzy based multiple performance characteristics index (MPCI) with particle swarm optimization (PSO) is used to find out the multiobjective optimal design solution. Both of the torque and speed are expected to be maximal at the same time. Three control factors are selected as studied factors: winding diameter, winding type, and air-gap. Experimental results show that both of the torque and speed increase under the optimal condition. This will provide enough large torque and speed to perform the turbo injection mode in injection process for the injection molding machine.
\end{abstract}

\section{Introduction}

Axial-flux motor is widely applied in the technical field of direct-drive mechanism. Different from the radial-flux motor, the axial-flux type motor has larger torque, shorter axial length, and more compact structure. Therefore, the axial-flux type motor is applied in many electric vehicle and industrial automation applications [1].

The fractional concentrated winding and fractional distributed winding have advantages of shorter wiring length, lower copper loss and lower m.m.f. harmonics [2]. Therefore, the axial-flux motor has lower inductance values $[3,4]$. If the motor requires operating under wider speed range, large demagnetizing current is required to generate the weak field effect [4].

The permanent magnet is embedded into rotor structure to provide more compact force [5]. Fractional slot design is selected to provide appropriate design for the stator structure [6]. Consequently, axial-flux motor is usually used in high torque application [7].

This paper proposes a compact design for the injection molding process. Axial-flux motor is used to provide the required injection force. Two-wye-wye winding structure is proposed to provide two different levels of speed range.

That means wider speed range is designed. By setting two energizing current commands and switch two modes for two wye-wye windings, wider speed and higher torque are achieved. Turbo injection mode is designed by energizing winding current in one specific wye winding.

This will be very helpful to provide larger torque for the injection molding machine. The conventional injection molding machine requires a huge hydraulic pressure structure to provide enough larger force. However, the hydraulic pressure structure occupies very large space. The overall 
TABLE 1: Selected control factors and noise factors.

\begin{tabular}{lccc}
\hline Factor & \multicolumn{3}{c}{ Level } \\
Level 1 & Level 2 & Level 3 \\
$\begin{array}{l}\text { (A) Wire } \\
\text { dimension }\end{array}$ & $4 \times 0.7 \mathrm{~mm}$ & $4 \times 1.0 \mathrm{~mm}$ & $4 \times 1.2 \mathrm{~mm}$ \\
$\begin{array}{l}\text { (B) Stator winding } \\
\text { (C) Air-gap }\end{array}$ & normal & overlap & Wye-wye \\
$\begin{array}{l}\text { (D) Insulation } \\
\text { layer thickness } \\
\text { (E) Temperature }\end{array}$ & $1.0 \mathrm{~mm}$ & $2.0 \mathrm{~mm}$ & $3.0 \mathrm{~mm}$ \\
\hline
\end{tabular}

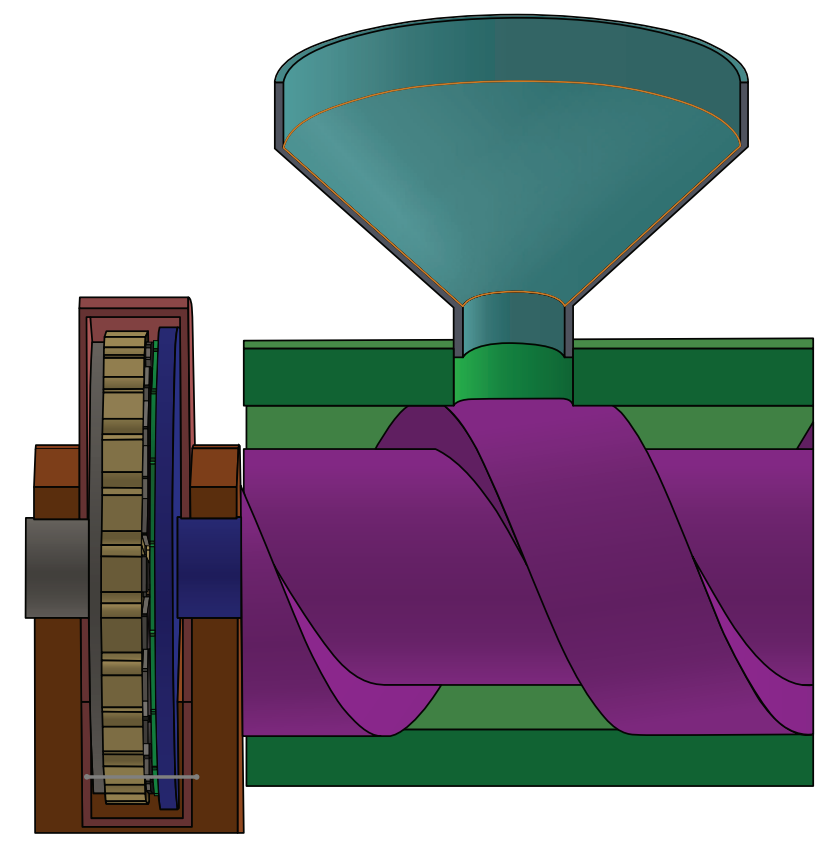

Figure 1: Axial-flux motor (on the left-hand side) in the plastic injection molding machine.

machine cannot be designed as a compact one. By using direct-drive type axial-flux motor, the injection molding machine can be designed more compactly.

\section{Design of Axial-Flux Motor in Plastic Molding Machine}

The axial-flux motor in the plastic injection molding machine is shown in Figures 1 and 2. The magnetic flux direction is in the axial direction. Two flat plates are placed face-to-face. There are three-phase windings on the stator plate. There are permanent magnets on the rotor plate.

24 slots and 16 poles are designed to provide the required magnetic propulsion force. The 3D model can be built up as shown from Figures 1 to 3 . After the 3D model is built up, the geometric model is imported into 3D software to analyze the magnetic field and assess the associated magnetic torque.

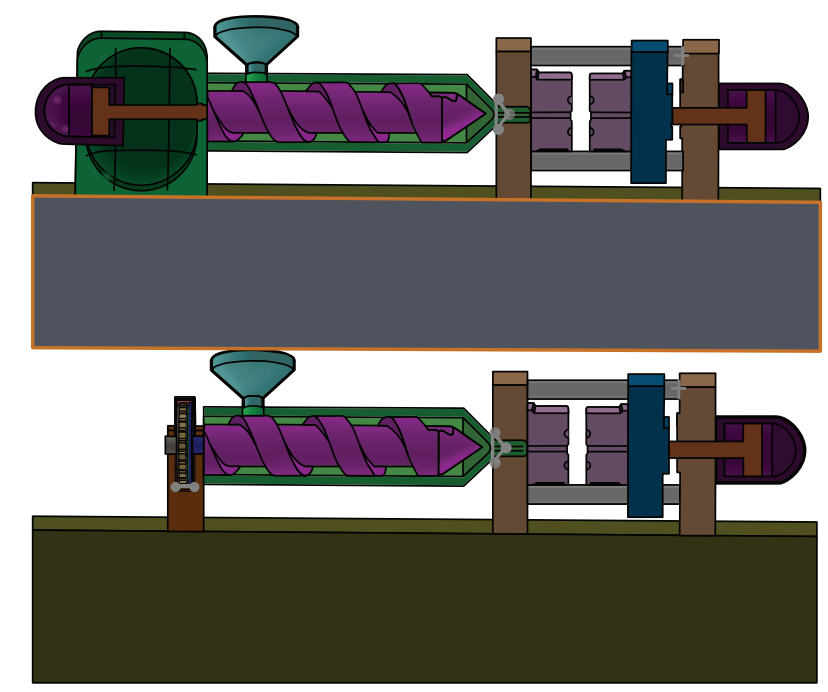

FIGURE 2: Comparison between conventional and improved plastic injection molding machine. More machine space is saved on lefthand side.

\section{Motor Operation and Turbo Injection Mode}

There are two techniques to design the turbo injection mode (TIM) characteristics of the motor: one is to regulate the field weakening and the other one is to regulate the torque constant [8].

Figure 4 shows the wye-delta winding configuration and control scheme for six power switches $[9,10]$. The wye configuration can provide the required initial speed-up and required climbing torque demand. When the motor goes to the steady state, the motor changes its connection state from the wye configuration into delta configuration [11, 12].

The electric impedance of wye configuration is 3 times of the one of delta configuration. The back E.M.F. of wye configuration is 1.732 times of the one of delta configuration. Therefore, the torque of wye configuration is 1.732 times of the one of delta configuration. The speed of delta configuration is 1.732 times of the one of wye configuration.

In order not to generate too higher instant acceleration, dual-duty control method is used. It is easy for the wye-wye configuration to prevent from generating too large transient current when switching from the wye-wye configuration to only one wye winding configuration. The current control loop is also used to reduce the transient current for safety and protection $[13,14]$. Figure 5 shows the block diagram of the overall control system [15].

\section{Response Surface Method with Fuzzy MPCI Method}

From practical applications, there are many control factors to increase the speed of the axial-flux motor as shown in Table 1. Three factors are considered and selected in this paper. The first one is wiring dimension. The second one is winding type. The third one is air-gap. The three factors are used to define the three control factors for the response surface method. 
TABLE 2: Experimental combination table.

\begin{tabular}{|c|c|c|c|c|c|}
\hline Experiment & Wire dimension & Stator winding type & Air-gap & $\begin{array}{c}\text { Noise } 1 \\
\text { Insulation layer } \\
\text { thickness }\end{array}$ & $\begin{array}{c}\text { Noise } 2 \\
\text { Stator temperature }\end{array}$ \\
\hline 1 & -1 & -1 & -1 & -1 & 1 \\
\hline 2 & 1 & -1 & -1 & -1 & -1 \\
\hline 3 & -1 & 1 & -1 & -1 & -1 \\
\hline 4 & 1 & 1 & -1 & -1 & 1 \\
\hline 5 & -1 & -1 & 1 & -1 & -1 \\
\hline 6 & 1 & -1 & 1 & -1 & 1 \\
\hline 7 & -1 & 1 & 1 & -1 & 1 \\
\hline 8 & 1 & 1 & 1 & -1 & -1 \\
\hline 9 & -1 & -1 & -1 & 1 & -1 \\
\hline 10 & 1 & -1 & -1 & 1 & 1 \\
\hline 11 & -1 & 1 & -1 & 1 & 1 \\
\hline 12 & 1 & 1 & -1 & 1 & -1 \\
\hline 13 & -1 & -1 & 1 & 1 & 1 \\
\hline 14 & 1 & -1 & 1 & 1 & -1 \\
\hline 15 & -1 & 1 & 1 & 1 & -1 \\
\hline 16 & 1 & 1 & 1 & 1 & 1 \\
\hline
\end{tabular}

TABLE 3: Central-point experiments.

\begin{tabular}{lccccc}
\hline Experimental & Wire dimension & Stator winding type & Air-gap & $\begin{array}{c}\text { Noise 1 } \\
\text { Insulation layer } \\
\text { thickness }\end{array}$ & $\begin{array}{c}\text { Noise 2 } \\
\text { Stator temperature }\end{array}$ \\
\hline 1 & 0 & 0 & 0 & 0 & 0 \\
2 & 0 & 0 & 0 & 0 & 0 \\
3 & 0 & 0 & 0 & 0 & 0 \\
4 & 0 & 0 & 0 & 0 & 0 \\
\hline
\end{tabular}

The optimal solution is obtained by using response surface method. Figure 6 shows the membership function definition for the described design problem.

The multiobjective design problem for the axial-flux motor is to maximize the torque and to maximize speed at the same time. As shown in Table 1, there are three control factors selected for the associated motor design: the diameter of the wiring, the type of the wiring, and the width of air-gap. For the response surface method, two noise factors are required for the associated ANOVA. They are insulating coefficient and the stator temperature. The required experimental data are provided in Tables 1 5.

\section{Analysis of Response Surface Method}

The average of the four central-point experimental values in Table 5 can be calculated as

$$
\begin{aligned}
\bar{y}_{c} & =\frac{(0.494493+0.498346+0.509634+0.510584)}{4} \\
& =0.5033 .
\end{aligned}
$$

The average of the response data for the sixteen experimental runs shown 6 in Table 4 can be calculated as

$$
\begin{aligned}
\bar{y}_{f}= & (0.347434+0.491050+0.541886 \\
& +0.688483+0.492251+0.57211 \\
& +0.975190+0.365364+0.491021 \\
& +0.540572+0.694721 \\
& +0.491722+0.570795 \\
& +0.713033+0.968653) \cdot(16)^{-1} \\
= & 0.6035 .
\end{aligned}
$$

Therefore, the curvature sum of squares can be further calculated as follows:

$$
\begin{aligned}
\mathrm{SS}_{C} & =\frac{n_{f} n_{c}\left(\bar{y}_{f}-\bar{y}_{c}\right)^{2}}{n_{f}+n_{c}}=\frac{16 \times 4(0.6035-0.5033)^{2}}{16+4} \\
& =0.032156 .
\end{aligned}
$$




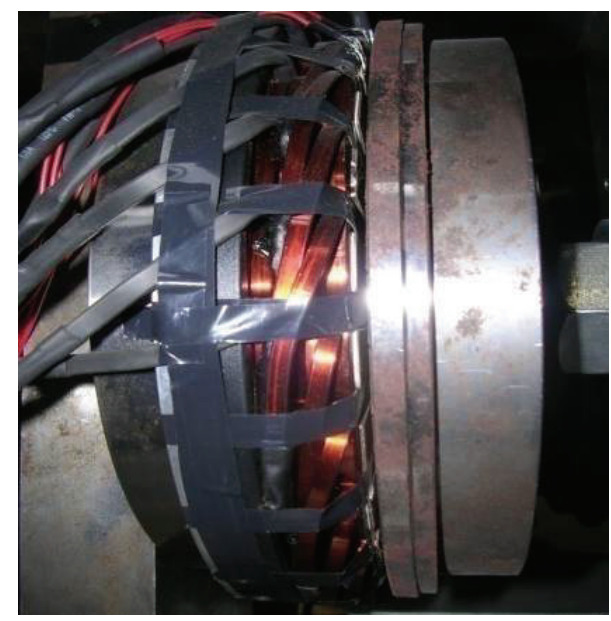

(a) Stator

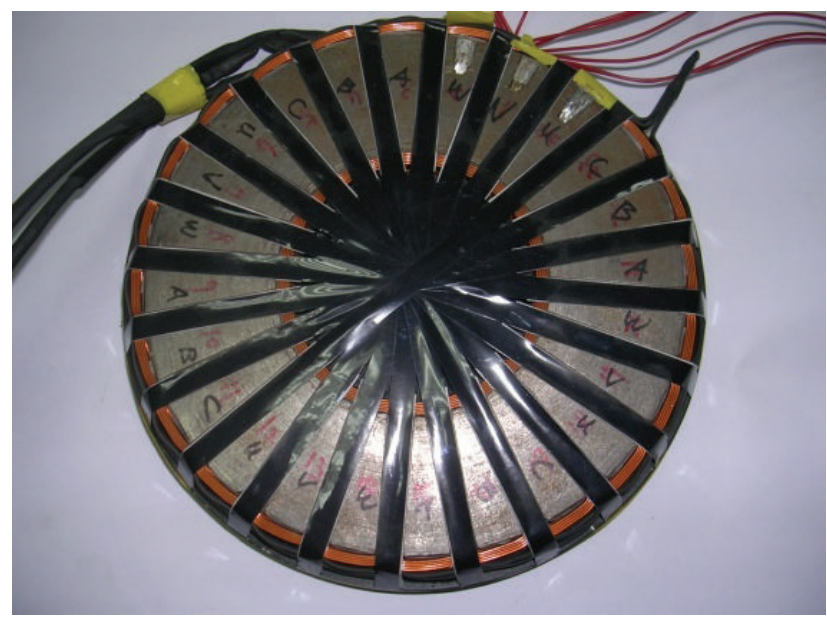

(b) Rotor

FIgURE 3: Practical experimental prototype for axial-flux motor.

TABLE 4: MPCI-based experimental runs.

\begin{tabular}{lcc}
\hline Speed (rpm) & $\begin{array}{c}\text { Torque } \\
(\mathrm{N} \cdot \mathrm{m})\end{array}$ & $\begin{array}{c}\text { Fuzzy inference result for MPCI } \\
\text { (normalized) }\end{array}$ \\
\hline 363 & 1.011 & 0.34743 \\
479 & 1.132 & 0.49105 \\
615 & 1.351 & 0.54189 \\
811 & 1.611 & 0.68848 \\
501 & 1.152 & 0.49225 \\
661 & 1.423 & 0.57211 \\
848 & 1.642 & 0.71184 \\
1119 & 1.862 & 0.97519 \\
364 & 1.022 & 0.36536 \\
480 & 1.131 & 0.49102 \\
613 & 1.341 & 0.54057 \\
814 & 1.632 & 0.69472 \\
500 & 1.141 & 0.49172 \\
659 & 1.412 & 0.57080 \\
846 & 1.65 & 0.71303 \\
1120 & 1.842 & 0.96865 \\
\hline
\end{tabular}

The error sum of squares is computed as

$$
\mathrm{SS}_{E}=\sum_{i=1}^{n_{c}}\left(y_{m}-\bar{y}_{c}\right)^{2}=0.000195 \text {. }
$$

$F$ statistical value is calculated as

$$
F=\frac{\mathrm{SS}_{c} / 1}{\mathrm{SS}_{E} /\left(n_{c}-1\right)}=\frac{0.032156 / 1}{0.000195 /(4-1)}=493.993598
$$

The ANOVA analysis for the first-order response surface model is evaluated by software-based regressive analysis. Due to limited pages, the ANOVA tables are neglected.
TABLE 5: MPCI based central-point experiments.

\begin{tabular}{lcc}
\hline Speed & Torque & $\begin{array}{c}\text { Fuzzy } \\
\text { inference } \\
\text { result }\end{array}$ \\
\hline 568 & 1.192 & 0.49449 \\
569 & 1.203 & 0.49835 \\
568 & 1.245 & 0.50963 \\
570 & 1.246 & 0.51058 \\
\hline
\end{tabular}

From the above equation, the curvature is very small. Therefore, the first-order model can be used to evaluate the optimal parameters. The first-order regressive model can be represented as follows. Assume that noise factors are zero, $z_{1}=0$, and $z_{2}=0$. The mean response surface can be obtained into

$$
\begin{aligned}
E_{z}(y(x, z))= & b_{0}+x^{\prime} b+x^{\prime} B x \\
= & Q_{1}+Q_{2} \cdot x_{1}+Q_{3} \cdot x_{2}+Q_{4} \cdot x_{3} \\
& +Q_{7} \cdot x_{1} x_{2}+Q_{8} \cdot x_{1} x_{3}+Q_{9} \cdot x_{2} x_{3} \\
= & 0.58346+0.078 \cdot x_{1}+0.12579 \cdot x_{2} \\
& +0.08344 \cdot x_{3}+0.02447 \cdot x_{1} x_{2} \\
& +0.00674 \cdot x_{1} x_{3}+0.02944 \cdot x_{2} x_{3} .
\end{aligned}
$$

The mean response surface can be plotted as $3 \mathrm{D}$ surface plot in Figure 7(a). Also, the corresponding contour plot can be plotted in Figure 7(b). 


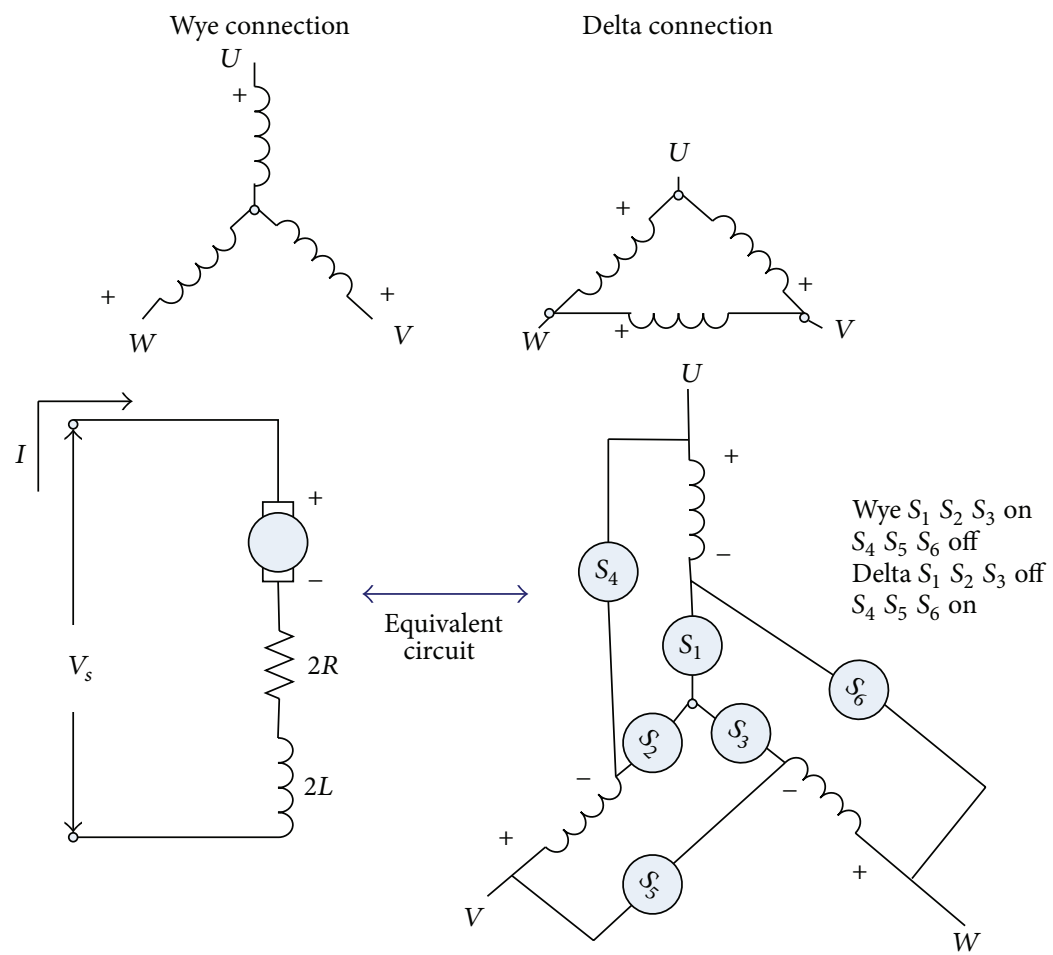

FIGURE 4: Wye-delta winding connection and control diagram for six power switches.

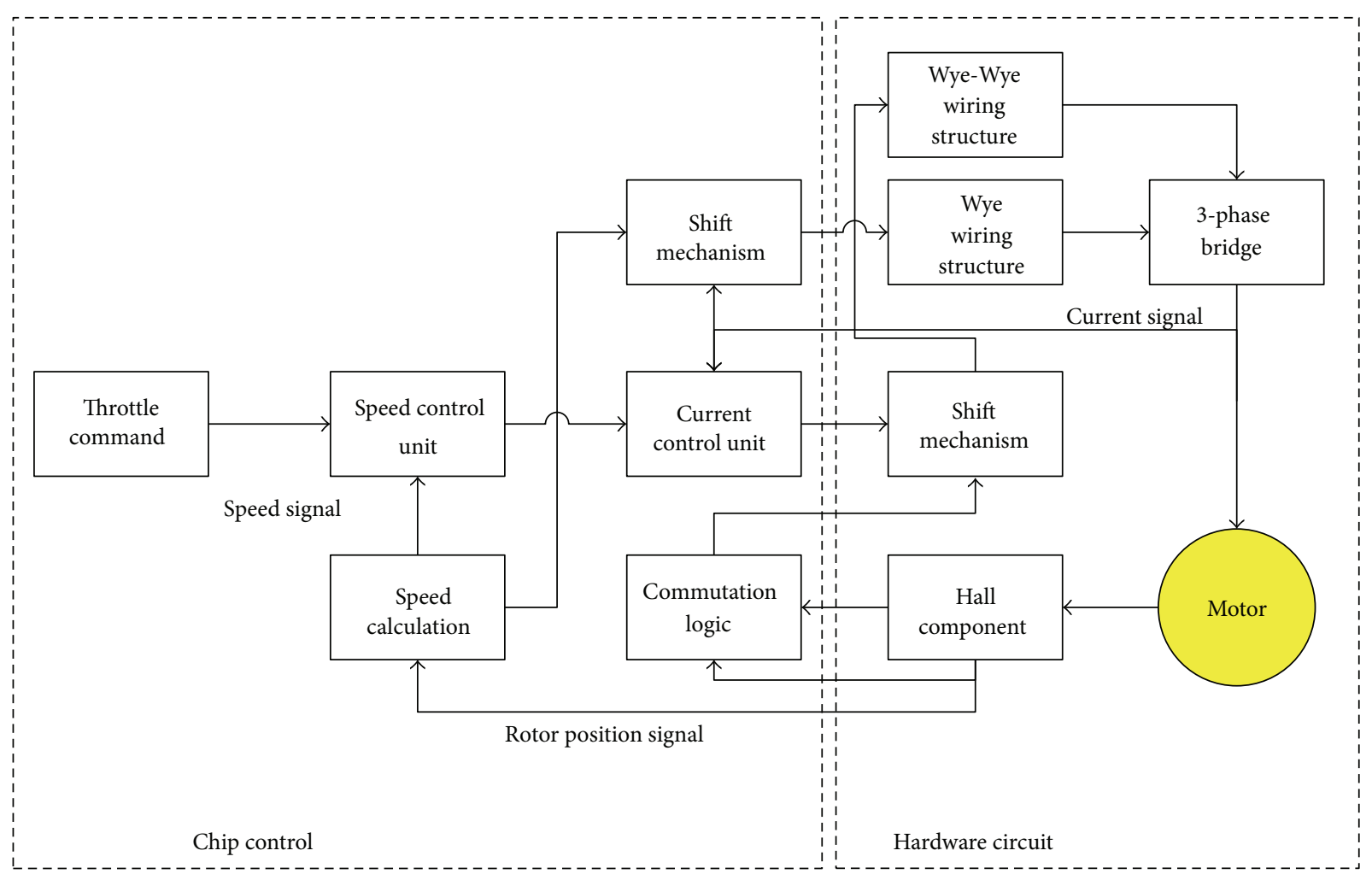

FIGURE 5: Block diagram of overall control system. 


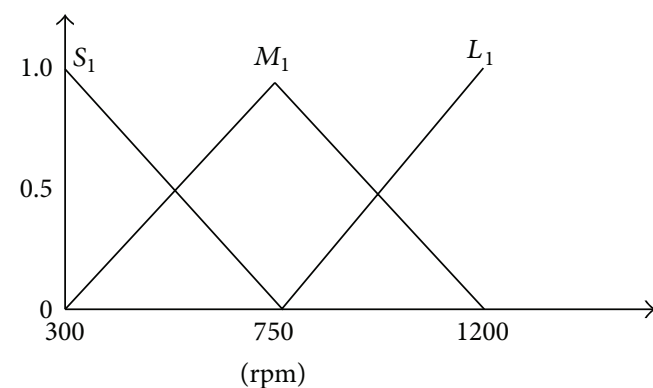

(a) Membership functions for speed

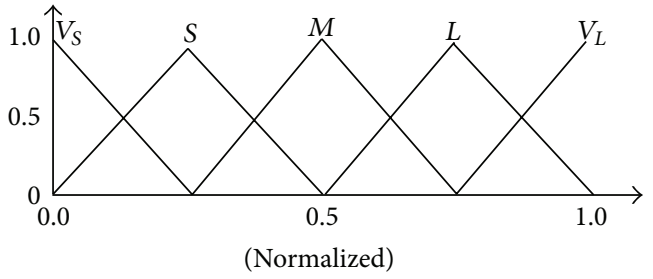

(c) Membership functions for MPCI

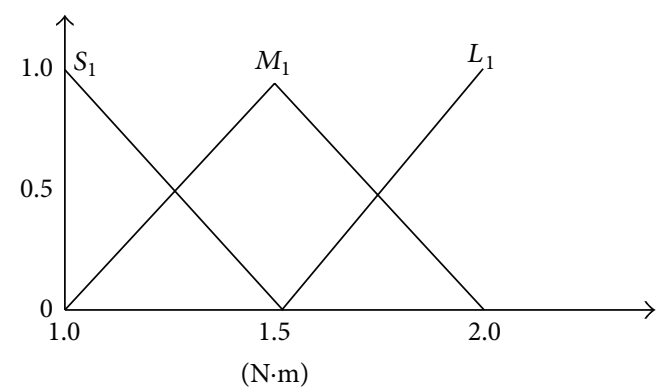

(b) Membership functions for torque

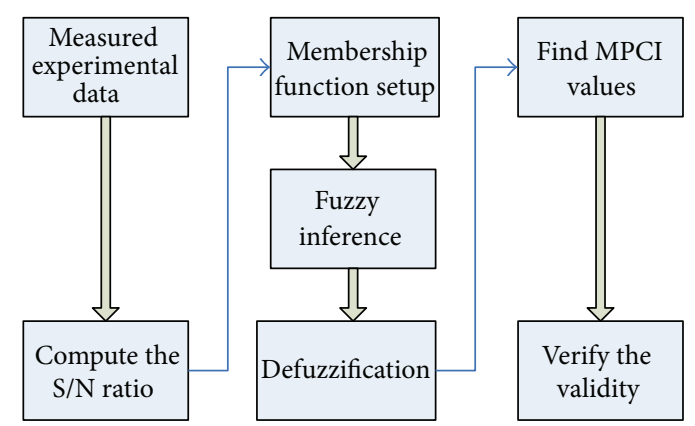

(d) Flow chart for MPCI method

FIGURE 6: Definition for membership functions. follows:

The variance response surface can be formulated as

$$
\begin{aligned}
\operatorname{Var}_{z}(y(x, z))= & \sum\left(\frac{\partial y}{\partial z_{i}}\right)^{2} \sigma_{z i}^{2}=\left(\frac{\partial y}{\partial z_{1}}\right)^{2} \sigma_{z 1}^{2}+\left(\frac{\partial y}{\partial z_{2}}\right)^{2} \sigma_{z 2}^{2}, \\
\frac{\partial y}{\partial z_{1}}= & 0.00098-0.00118 \cdot x_{1}-0.00103 \cdot x_{2} \\
& -0.001876 \cdot x_{3}, \\
\frac{\partial y}{\partial z_{2}}= & -0.00203 \cdot z_{2}+0.00059 \cdot x_{1}+0.00012 \cdot x_{2} \\
+ & 0.00116 \cdot x_{3} .
\end{aligned}
$$

Assume that $\sigma_{z 1}=1$ and $\sigma_{z 2}=1$, the variance response surface can be rewritten into

$$
\begin{aligned}
\operatorname{Var}_{z}(y(x, z))= & \left(5.07-4.71 \cdot x_{1}-2.49 \cdot x_{2}\right. \\
& -8.37 \cdot x_{3}+2.58 \cdot x_{1} x_{2}+5.81 \cdot x_{1} x_{3} \\
& +4.14 \cdot x_{2} x_{3}+1.75 \cdot x_{1}^{2}+1.07 \cdot x_{2}^{2} \\
& \left.+4.86 \cdot x_{3}^{2}\right) \times 10^{-6} .
\end{aligned}
$$

The 3D surface plot of variance response surface can be plotted as shown in Figure 8(a). Also, the corresponding contour plot can be shown in Figure 8(b). The constraint of the variance response surface can be described into

$$
\begin{aligned}
\operatorname{Var}_{z}(y(x, z))=( & \left(5.07-4.71 \cdot x_{1}-2.49 \cdot x_{2}\right. \\
& -8.37 \cdot x_{3}+2.58 \cdot x_{1} x_{2}+5.81 \cdot x_{1} x_{3} \\
& +4.14 \cdot x_{2} x_{3}+1.75 \cdot x_{1}^{2} \\
& \left.\left.+1.07 \cdot x_{2}^{2}+4.86 \cdot x_{3}^{2}\right) \times 10^{-6}\right) \leq 100
\end{aligned}
$$

where independent variable ranges are $-1.0 \leq x_{1} \leq 1.0$; $-1.0 \leq x_{2} \leq 1.0 ;-1.0 \leq x_{3} \leq 1.0$.

After the optimization problem is formulated, the optimization process by particle swarm method is used to search for the optimal solution.

\section{Particle Swarm Optimization Method}

With the above system model derived by response surface method, the optimization process is performed to derive the optimal solution set for the described problem. However, the optimal solution may be located anywhere in the range between -1.0 and +1.0 . The local optimal solution may not be the optimal in the entire global region. Therefore, the PSO process is used to derive the optimal solution in an efficient way. The local searching and global searching go simultaneously. Therefore, global optimal solution can be found.

By adding the random seeds into formulation, the PSO can jump out of the local optimal solution if the global 


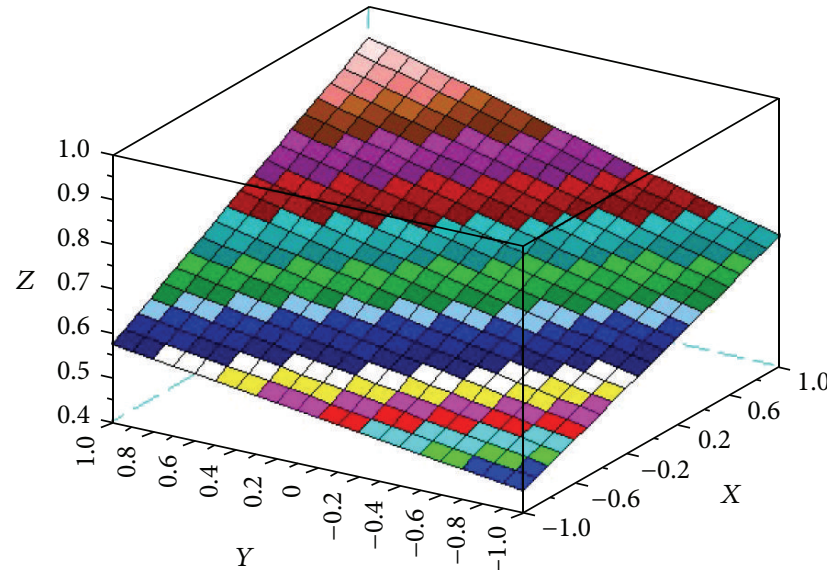

(a) $3 \mathrm{D}$ surface plot

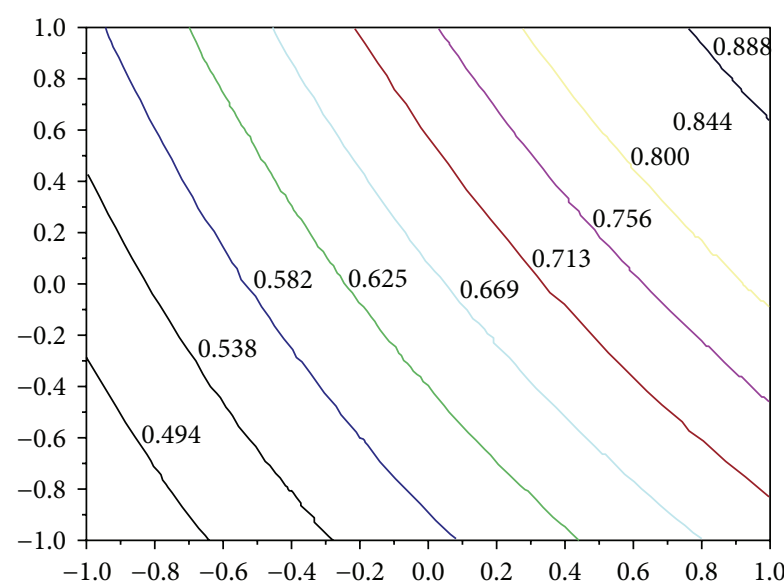

(b) Contour plot

Figure 7: The mean response surface.

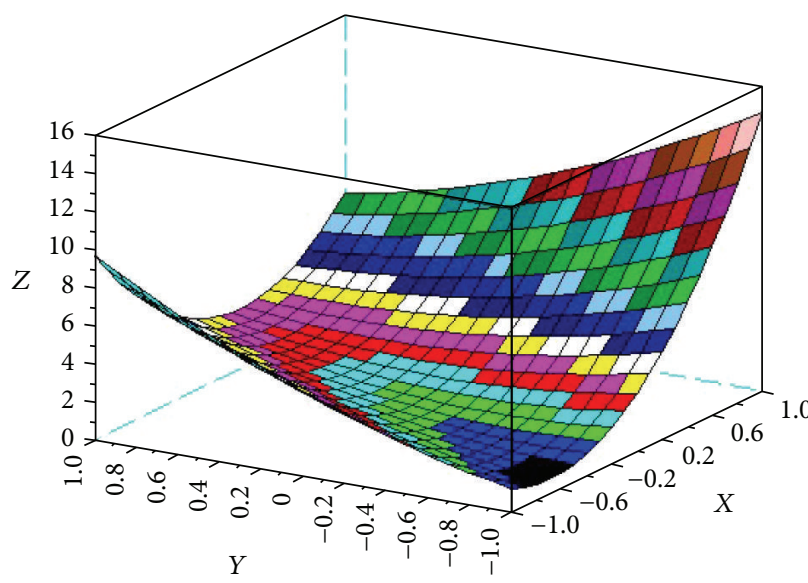

(a) 3D surface plot

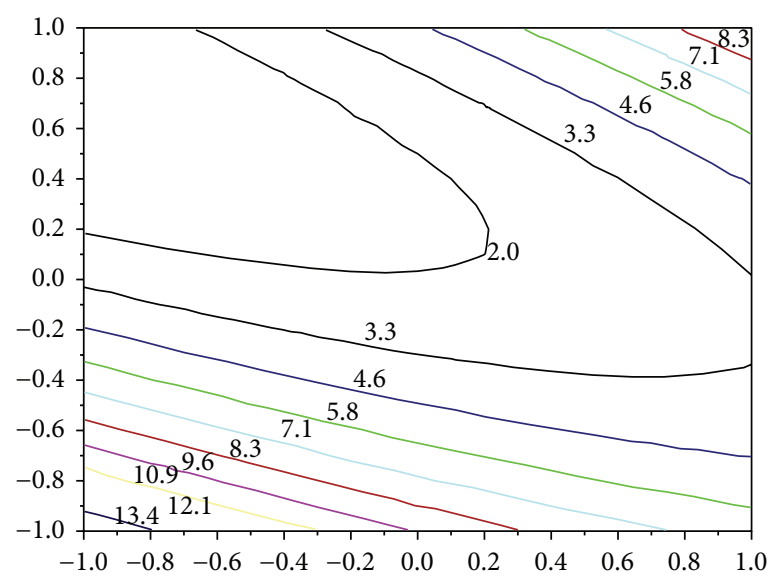

(b) Contour plot

Figure 8: The variance response surface.

solution is more optimal than the local solution. In the following, the OPSO (orthogonal particle swarm optimization) formulation is performed. Since in the response surface method, the nonlinear problem is formulated as first-order model problem. However, the curvature for this model affects the precision when finding the optimal solution. That means the nonlinearity property exists in this problem. This influences the searching process when finding the optimal solution.

The particle swarm optimization originates from the emulation of the group dynamic behavior of animal. For each particle in a group, it is not only affected by its respective particle, but also affected by the overall group. There are position and velocity vectors for each particle. The searching method combines the experience of the individual particle with the experience of the group. For a particle or a point in a searching space with $D$-dimension $[16,17]$, the $i$ th particle associated with the problem can be defined as

$$
X_{i d}=\left(x_{i 1}, x_{i 2}, \ldots, x_{i D}\right),
$$

where $d=1,2, \ldots, D$ and $i=1,2, \ldots$, PS, PS is the population size. The respective particle objective function and group objective function associated with each $X_{i d}$ are defined as $[18,19]$

$$
\begin{aligned}
& P_{p d}=\left(p_{p 1}, p_{p 2}, \ldots, p_{p D}\right), \\
& P_{g d}=\left(p_{g 1}, p_{g 2}, \ldots, p_{g D}\right) .
\end{aligned}
$$

The refreshing speed vector can be defined as

$$
V_{i d}=\left(v_{i 1}, v_{i 2}, \ldots, v_{i D}\right) .
$$

The refreshing position and velocity vectors can be expressed as $[20,21]$

$$
\begin{aligned}
V_{i d}^{n+1}= & V_{i d}^{n}+c_{1} \times \operatorname{rand}() \times\left(P_{p d}-X_{i d}^{n}\right) \\
& +c_{2} \times \operatorname{rand}() \times\left(P_{g d}-X_{i d}^{n}\right),
\end{aligned}
$$

where $X_{i d}^{n+1}=X_{i d}^{n}+V_{i d}^{n}$. 
When the searching begins, the initial solution is set. In the iteration process, the particle is updated by the value coming from the group particles and individual particle. The convergence condition is dependent on the minimum of the average square error of the particle. Both the experience of the individual particle and the experience of the group are mixed into the searching process $[22,23]$.

In the optimization problem, there might be a local minimum problem. The optimal solution might jump into a local trap and cannot jump out of the trap $[24,25]$. Actually, a local minimum point does not represent a global solution in a wide range. In the group experience, random function is used to jump out of the local interval. An inertia weighting factor is considered in this algorithm to increase the convergence rate. An inertia weighting factor is added in the following expression [26]. The modified formula can be expressed as

$$
\begin{aligned}
V_{i d}^{n+1}= & W \times V_{i d}^{n}+c_{1} \times \operatorname{rand}() \times\left(P_{p d}-X_{i d}^{n}\right) \\
& +c_{2} \times \operatorname{rand}() \times\left(P_{g d}-X_{i d}^{n}\right), \\
W & =W_{\max }-\frac{W_{\max }-W_{\min }}{\operatorname{gen}_{\max }} \times \text { gen },
\end{aligned}
$$

where the $c_{1}$ and $c_{2}$ are both constants. $W_{\max }$ is the initial weighting value. $W_{\min }$ is the final weighting value. gen is the number of current generation. gen $\mathrm{max}_{\max }$ is the number of final generation. However, the above mentioned is actually a kind of linear modification. To make the algorithm suitable for nonlinear searching problem, there is many nonlinear modification methods proposed to refresh the velocity vector. The modified term is defined as the key factor. By setting the learning factors $c_{1}$ and $c_{2}$ which are larger than 4.0, the modification for the speed vector is expressed into

$$
\begin{gathered}
V_{i d}^{n+1}=K \times\left[V_{i d}^{n}+c_{1} \times \operatorname{rand}() \times\left(P_{p d}-X_{i d}^{n}\right)\right. \\
\left.+c_{2} \times \operatorname{rand}() \times\left(P_{g d}-X_{i d}^{n}\right)\right], \\
K=\frac{2}{\left|2-\left(c_{1}+c_{2}-\sqrt{\left(c_{1}+c_{2}\right)^{2}-4 \times\left(c_{1}+c_{2}\right)}\right)\right|} .
\end{gathered}
$$

A modified PSO method called orthogonal PSO (OPSO) is proposed to solve the update problem effectively. A simple orthogonal array in Taguchi method is used in this algorithm to help with the update [26].

\section{Orthogonal Array Algorithm in OPSO Method}

To run the Taguchi method, two functions are defined first. The particle swarms are composed of individual particle swarm $O_{i d}$ and group particle swarm $A_{i d}$

$$
\begin{aligned}
& O_{i d}=X_{i d}^{n}+W V_{i d}^{n}+c_{1} \times \operatorname{rand}() \times\left(P_{p d}-X_{i d}^{n}\right), \\
& A_{i d}=X_{i d}^{n}+W V_{i d}^{n}+c_{2} \times \operatorname{rand}() \times\left(P_{g d}-X_{i d}^{n}\right) .
\end{aligned}
$$

These two functions are specified as two control factors in Taguchi method. Two levels are defined for the control factors. Therefore, the orthogonal array has two factors and two levels. The objective function calculating from the problem is used as the measured value in orthogonal array. By comparing the objective function value in the orthogonal array, the optimal solution can be obtained. Assume that the optimal solution is expressed as $Q_{i d}$. The $Q_{i d}$ is adopted to refresh the particle position and velocity vectors as shown in the following expression. The particle refreshing process in OPSO optimization is illustrated in Figure 9

$$
\begin{gathered}
V_{i d}^{n+1}=Q_{i d}-X_{i d}^{n}, \\
X_{i d}^{n+1}=Q_{i d} .
\end{gathered}
$$

The optimization problem is formulated and the optimal solution can be found. The optimal speed and optimal torque can be found at the same time by using fuzzy MPCI method. The derived optimal solution can provide optimal condition for the associated motor design.

By using the response surface method combined with PSO method, the mathematical model for this problem is provided and verified. This will be very helpful to assess the associated motor design application. The optimal solution can be found and located at the ends of the entire searching range. Global solution is found instead of local solution. Results show that the proposed mathematical method has the capability of providing appropriate searching process.

The local optimal solution is avoided and the proposed PSO algorithm can find the optimal solution at the endpoints globally. In PSO, global and local optimal ranges are searched at the same time. The convergence rate is faster than conventional searching method. The related confirmation experiments show that the proposed methodology can provide good prediction with the practical experimental case.

It is convinced that the proposed optimal parameter solution solved by PSO algorithm can maximize both torque and speed for the motor design problem. In the response surface method, the $3 \mathrm{D}$ view of mean response surface and $3 \mathrm{D}$ view of variance response surface are plotted in Figures 7 and 8 . The maximal values of mean and variance can be observed in the figures. Also, the PSO process can be illustrated in Figure 9.

The final optimal solution is derived as $\left(x_{1}, x_{2}, x_{3}\right)=$ $(1.0,1.0,1.0)$. That is to say, the wiring dimension is set to $4 \times$ $1.2 \mathrm{~mm}$, stator wiring type is set to wye-wye, and the air-gap is set to $3.0 \mathrm{~mm}$. The optimal solution can have better torque and speed performance. The optimal solution set can also be shown up in the combinational table.

The speed is $1120 \mathrm{rpm}$ and the torque is $1.862 \mathrm{~N} \cdot \mathrm{m}$. The optimal MPCI index value is obtained as 0.931 . By averaging the 8 th and 16th experimental data in combinational table, the optimal torque and speed can be observed in combination table.

\section{Discussion}

The optimal solution set is located at the $(1.0,1.0,1.0)$. The optimal solution set means that the control factors with $A_{3}, B_{3}$, and $C_{3}$ are optimal for the described problem. The 


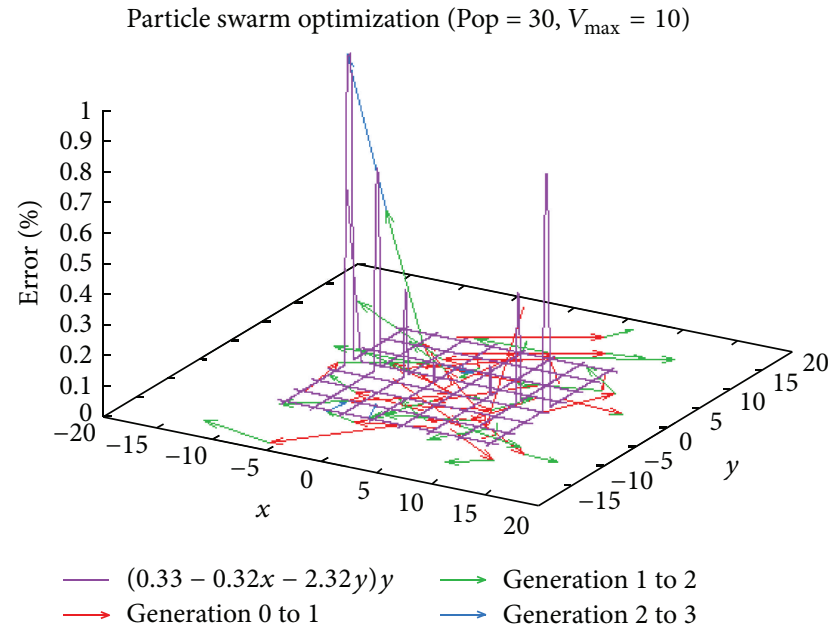

(a) Refreshing process from first generation to third generation

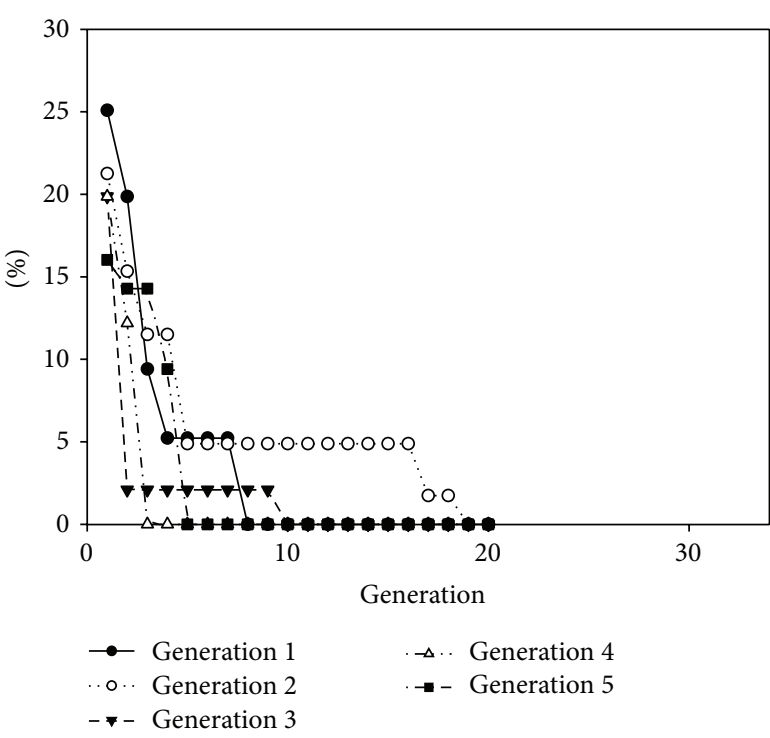

(b) Error percentage from first generation to fifth generation

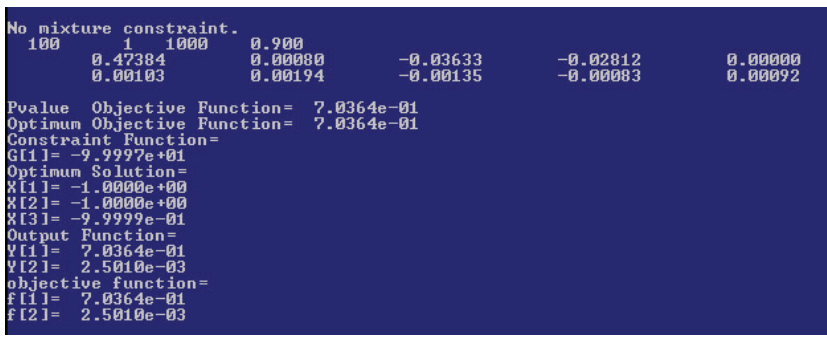

(c) Illustrated results for optimal solution

FIGURE 9: Illustrated PSO process for the optimization problem.

TABLE 6: Comparison among testing cases.

\begin{tabular}{|c|c|c|c|}
\hline & $\begin{array}{c}\text { Speed } \\
\text { experiments }\end{array}$ & $\begin{array}{c}\text { Torque } \\
\text { experiments }\end{array}$ & $\begin{array}{l}\text { Torque and speed } \\
\text { experiments }\end{array}$ \\
\hline $\begin{array}{l}\text { Analysis } \\
\text { method }\end{array}$ & $\begin{array}{l}\text { Dual response } \\
\text { surface method }\end{array}$ & $\begin{array}{l}\text { Dual response surface } \\
\text { method }\end{array}$ & $\begin{array}{c}\text { Fuzzy MPCI } \\
\text { inference dual } \\
\text { response surface method }\end{array}$ \\
\hline $\begin{array}{l}\text { Objective } \\
\text { function }\end{array}$ & The higher the better & The higher the better & The higher the better \\
\hline Level design & Isometric & Isometric & Isometric \\
\hline $\begin{array}{l}\text { Optimal } \\
\text { combination }\end{array}$ & $\mathrm{A}_{3} \mathrm{~B}_{3} \mathrm{C}_{3}$ & $\mathrm{~A}_{3} \mathrm{~B}_{3} \mathrm{C}_{3}$ & $\mathrm{~A}_{3} \mathrm{~B}_{3} \mathrm{C}_{3}$ \\
\hline Combination table value & $1120(\mathrm{rpm})$ & $1.862(\mathrm{~N} \cdot \mathrm{m})$ & $\begin{array}{c}1120(\mathrm{rpm}) \\
1.862(\mathrm{~N} \cdot \mathrm{m})\end{array}$ \\
\hline Mathematical optimization & $1094.4(\mathrm{rpm})$ & $1.844(\mathrm{~N} \cdot \mathrm{m})$ & $\begin{array}{l}1119.5(\mathrm{rpm}) \\
1.852(\mathrm{~N} \cdot \mathrm{m})\end{array}$ \\
\hline
\end{tabular}

resultant data for three studied cases are compared in Table 6. Fuzzy MPCI method is used to achieve the multiobjectives design. Both the torque and the speed keep at maximal values at the same time. Based on the derived multiobjective solution set, the maximal speed is $1119.5 \mathrm{rpm}$ and the maximal force is $1.852 \mathrm{~N} \cdot \mathrm{m}$. Also, in the combination table, the experimental speed $1120 \mathrm{rpm}$ and experimental force $1.862 \mathrm{~N} \cdot \mathrm{m}$ can be found. Therefore, the optimal solution has good coincidence with the experimental data in combination table.

\section{Conclusion}

Maximal optimal values are obtained for both of the two multiobjective functions when the optimal control factor solution set is selected. The torque and speed characteristics keep at 
maximal values at the same time. Fuzzy MPCI method is used to perform the multiobjective design. Response surface method is used to derive the associated mathematical model for the studied system. It is very useful to squeeze the plastic material into molding area and provide enough squeezing pressure for the injection molding machine. The plastic material can be further condensed. The design purpose of turbo injection mode (TIM) for the axial-flux motor is achieved. The improved TIM molding process can provide better product quality for the associated molding manufacturing process.

\section{Conflict of Interests}

The authors declare that there is no conflict of interests regarding the publication of this paper.

\section{References}

[1] A. Mebarki, K. Wejrzanowski, M. Shanel, and N. L. Brown, "A high-power, totally enclosed, permanent magnet, axial flux machine for engine integration," in Proceedings of the 5th IET International Conference on Power Electronics, Machines and Drives, (PEMD '10), pp. 1-6, April 2010.

[2] A. M. EL-Refaie, "Fractional-slot concentrated-windings synchronous permanent magnet machines: opportunities and challenges," IEEE Transactions on Industrial Electronics, vol. 44, no. 1, pp. 107-121, 2010.

[3] W. L. Soong and T. J. E. Miller, "Field-weakening performance of brushless synchronous AC motor drives," IEE Proceedings: Electric Power Applications, vol. 141, no. 6, pp. 331-340, 1994.

[4] M. Aydin, S. Huang, and T. A. Lipo, "A new axial flux surface mounted permanent magnet machine capable of field control," in Proceedings of the 37th IAS Annual Meeting of the Industry Applications Conference, vol. 2, pp. 1250-1257, Pittsburgh, Pa, USA, October 2002.

[5] A. Cavagnino, M. Lazzari, F. Profumo, and A. Tenconi, "Axial flux interior PM synchronous motor: parameters identification and steady-state performance measurements," IEEE Transactions on Industry Applications, vol. 36, no. 6, pp. 1581-1588, 2000.

[6] T.-S. Kwon, S.-K. Sul, L. Alberti, and N. Bianchi, "Design and control of an axial flux machine for a wide flux-weakening operation region," in Proceedings of the 42nd IAS Annual Meeting on Industry Applications Conference, pp. 2175-2182, New Orleans, La, USA, September 2007.

[7] A. M. EL-Refaie, T. M. Jahns, P. J. McCleer, and J. W. McKeever, "Experimental verification of optimal flux weakening in surface PM machines using concentrated windings," IEEE Transactions on Industry Applications, vol. 42, no. 2, pp. 443-453, 2006.

[8] J. L. Colton, Design of an integrated starter-alternator for a series hybrid electric vehicle: a case study in axial flux permanent magnet machine design [A Dissertation Presented to the Faculty of the Graduate College at the University of Nebraska in Partial Fulfillment of Requirements for the Degree of Doctor of Philosophy], Electrical Engineering Theses and Dissertations, paper 12, pp. 27-31, 2010.

[9] J. Colton, D. Patterson, J. Hudgins, and K. Vacha, "Generator design for existent windmills: from water pumping to electricity generation," in Proceedings of the IEEE Power Electronics and Machines in Wind Applications (PEMWA '09), June 2009.

[10] B. G. Wang, S. H. Wang, J. Q. Huang, M. Y. Cheng, and M. Q. Cai, "Light electric hub motor vehicle design with electronic variable speed control technology," Electric Monthly, vol. 20, no. 8, pp. 140-148, 2010.

[11] Z. Y. Lin, With reliability and high-performance electric vehicle drive system design and implementation [M.S. thesis], Department of Mechanical Engineering, National Cheng Kung University, 2009.

[12] B. Sun and Z. Wu, "Optimization of injection molding process parameters based on response surface methodology and genetic algorithm," in Proceedings of the IEEE 2nd International Conference on Computer Engineering and Technology, pp. 397-400, 2010.

[13] M. S. Yeoman, "Multiphase, dual polymer injection molding and cooling of an open cavity to form both distinct and graduated material properties within a complex three-dimensional body," in Proceedings of the COMSOL Conference, Bostan, Iran, 2009.

[14] P. B. S. Reddy, K. Nishina, and A. S. Babu, "Taguchi’s methodology for multi-response optimization: a case study in the Indian plastics industry," International Journal of Quality and Reliability Management, vol. 15, no. 6, pp. 646-668, 1998.

[15] C. W. Hung and C. Y. Huang, Optimization for plastic injection molding operations by dual response surface method and nonlinear programming [M.S. thesis], Department of Industrial Engineering, Tunghai University, 1998.

[16] Z.-L. Gaing, "A particle swarm optimization approach for optimum design of PID controller in AVR system," IEEE Transactions on Energy Conversion, vol. 19, no. 2, pp. 384-391, 2004.

[17] C. C. Hang, K. J. Astrom, and W. K. Ho, "Refinements of the Ziegler-Nichols tuning formula," IEE Proceedings D: Control Theory and Applications, vol. 138, no. 2, pp. 111-118, 1991.

[18] Z. Malik and K. Rashid, "Comparison of optimization by response surface methodology with neurofuzzy methods," IEEE Transactions on Magnetics, vol. 36, no. 1, pp. 241-257, 2000.

[19] H. J. Zimmermann, Fuzzy Set Theory and Its Applications, Kluwer Academic Publishers, London, UK, 1985.

[20] Z. L. Gaing and J. A. Chiang, "Robust design of in-wheel PM motor by fuzzy-based Taguchi method," in Proceedings of the IEEE Power and Energy Society General Meeting, pp. 1-7, Minneapolis, Minn, USA, July 2010.

[21] Y. Shi and R. Eberhart, "A modified particle swarm optimization," in Proceedings of the IEEE International Conference on Evolutionary Computation, pp. 69-72, May 1998.

[22] R. C. Eberhart and Y. Shi, "Comparing inertia weights and constriction factors in particle swarm optimization," in Proceedings of the Congress on Evolutionary Computation (CEC '00), pp. 8488 , July 2000.

[23] S.-Y. Ho, H.-S. Lin, W.-H. Liauh, and S.-J. Ho, “OPSO: orthogonal particle swarm optimization and its application to task assignment problems," IEEE Transactions on Systems, Man, and Cybernetics Part A:Systems and Humans, vol. 38, no. 2, pp. 288298, 2008.

[24] J. Wang, S. Jin, S. Qin, and H. Jiang, "Swarm intelligencebased hybrid models for short-term power load prediction," 
Mathematical Problems in Engineering, vol. 2014, Article ID 712417, 17 pages, 2014.

[25] J. Li, X. Wang, J. Jia, P. Wang, Y. Zhou, and Z. Zhao, "Location prediction-based data dissemination using swarm intelligence in opportunistic cognitive networks," Mathematical Problems in Engineering, vol. 2014, Article ID 453564, 15 pages, 2014.

[26] L. Li, H. Huang, J. Lian et al., "Research of ant colony optimized adaptive control strategy for hybrid electric vehicle," Mathematical Problems in Engineering, vol. 2014, Article ID 239130, 10 pages, 2014. 


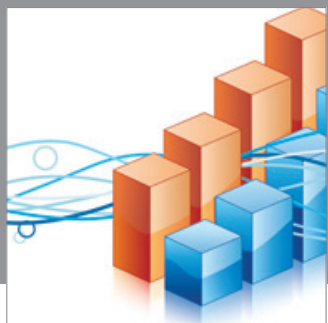

Advances in

Operations Research

mansans

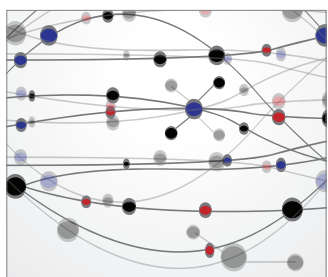

The Scientific World Journal
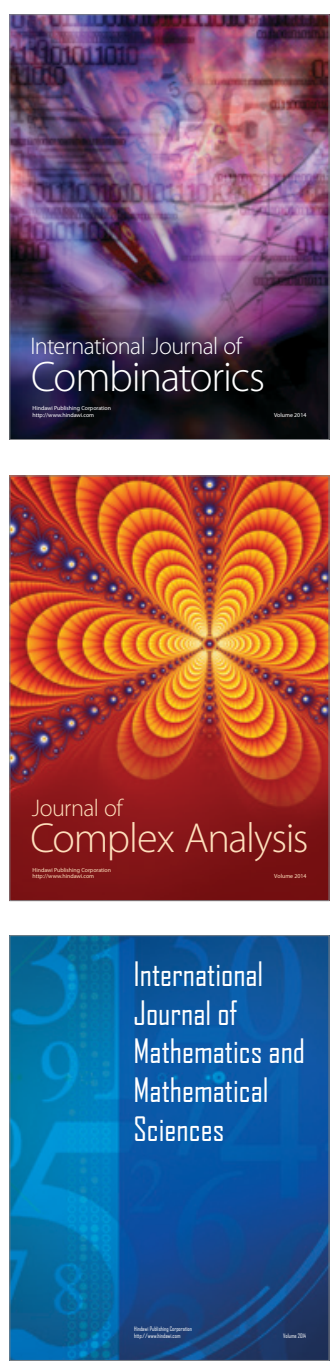
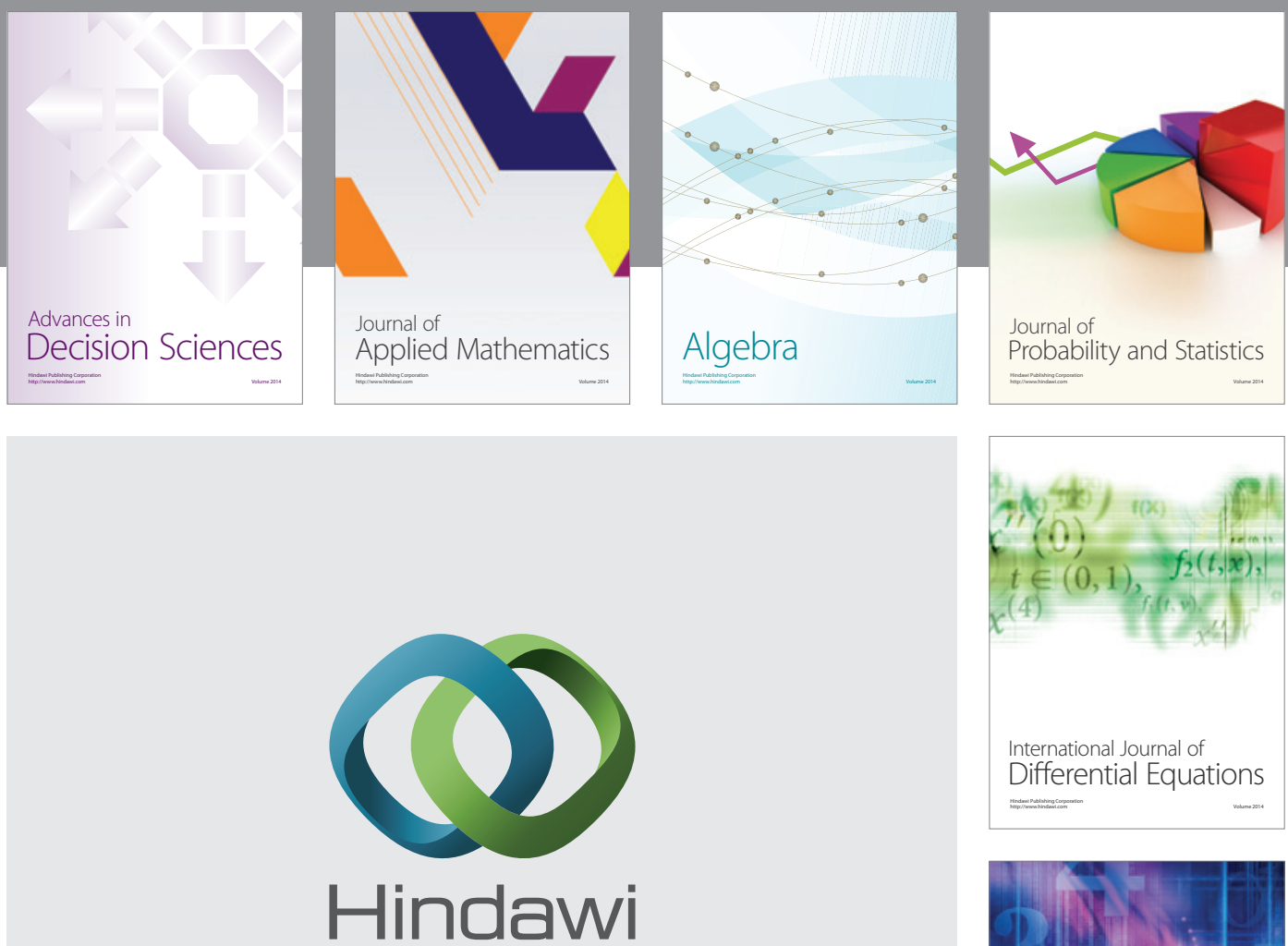

Submit your manuscripts at http://www.hindawi.com
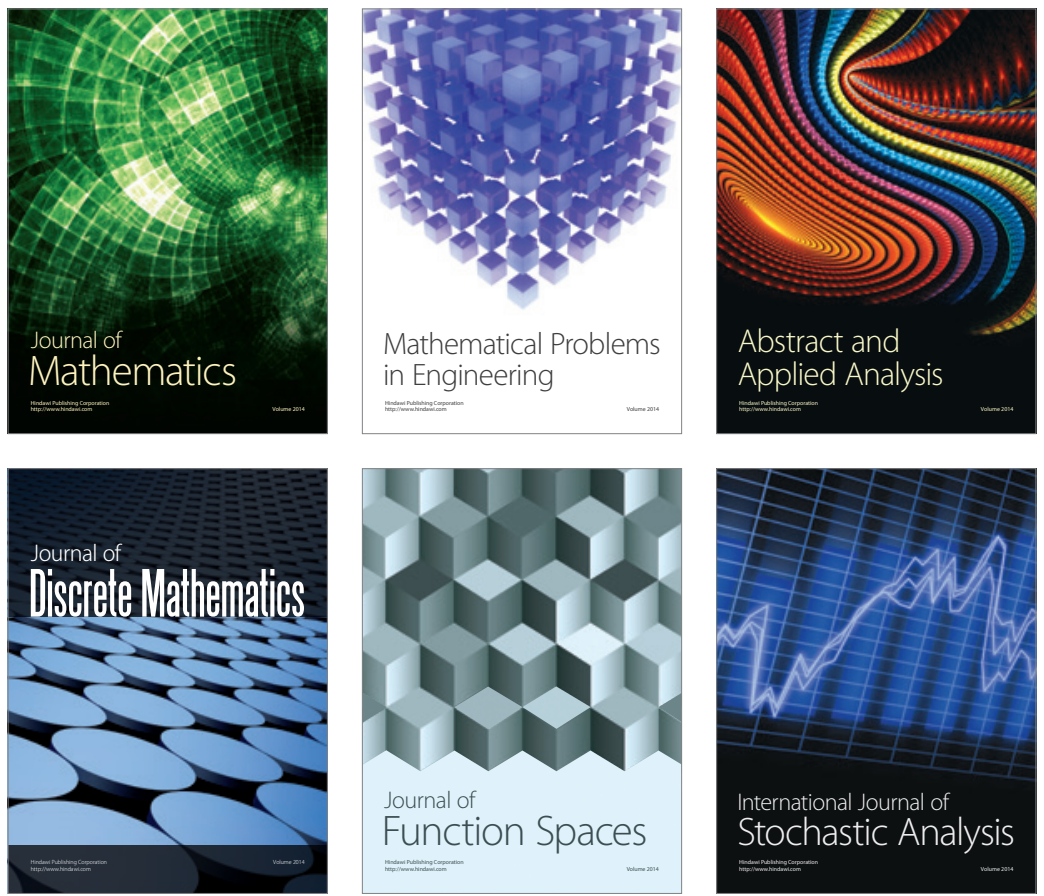

Journal of

Function Spaces

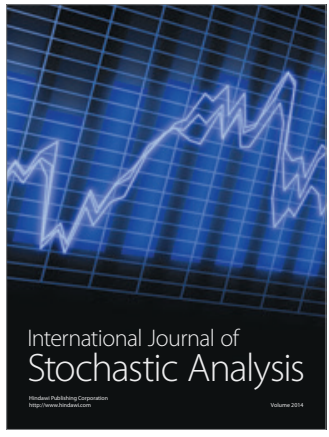

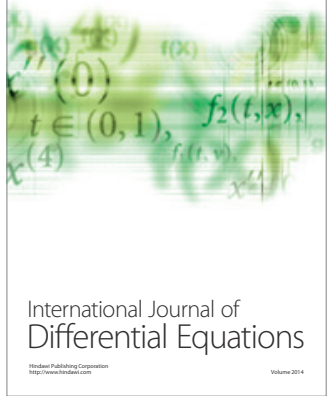
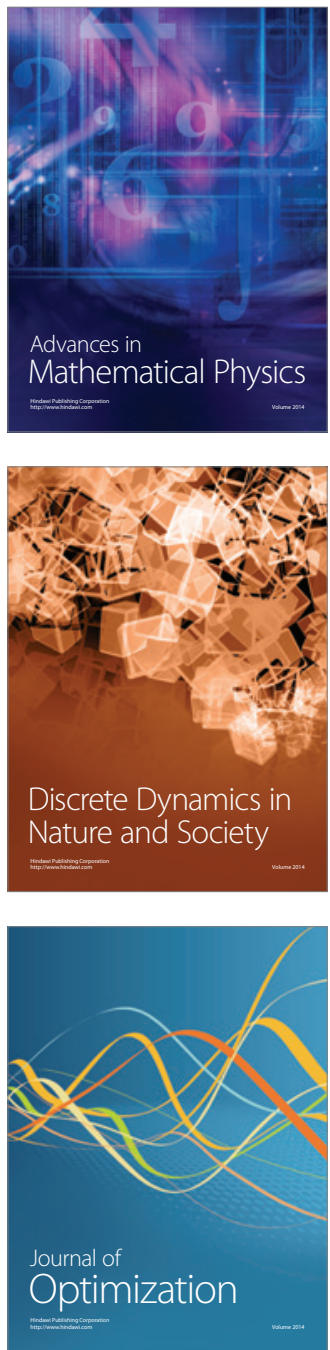